\title{
The pattern of basal and stimulated insulin responses to intravenous glucose in first degree relatives of Type 1 (insulin-dependent) diabetic children and unrelated adults aged 5 to 50 years
}

\author{
C.P.Smith ${ }^{1,2}$, A.J.K. Williams' ${ }^{2}$ J. M. Thomas ${ }^{2}$, H.R. Archibald ${ }^{2}$, V.D. Algar ${ }^{2}$, G. F. Bottazzo ${ }^{3}$, E. A. M. Gale ${ }^{2}$ and \\ M.O.Savage ${ }^{1}$ \\ ${ }^{1}$ Queen Elizabeth Hospital for Children, Department of Diabetes and Immunogenetics, ${ }^{2}$ St. Bartholomew's Hospital, and ${ }^{3}$ The Middlesex \\ Hospital, London, UK
}

\begin{abstract}
Summary. The pattern of insulin secretion was studied in 107 normal individuals aged 5 to 50 years. Intravenous glucose tolerance tests were performed on 64 islet-cell antibody negative siblings of diabetic children and on 43 normal adults. Puberty was staged using Tanner's criteria and subjects were grouped as follows: I - stage $1(n=22)$, II - stages 2 and 3 $(n=18)$, III - stages 4 and $5(n=20)$, IV - adults $>17$ years $(n=47)$. Basal and stimulated (incremental $0-10$ and $10-60 \mathrm{~min}$ areas) insulin responses rose throughout puberty (Groups I-III), declined following puberty until the third decade (Groups III and IV) and then appeared constant thereafter. Insulin levels in the 17.6-22.5 year group were lower than in the $12.6-15$ year group $(p<0.01)$. Fasting insulin to
\end{abstract}

glucose ratios and incremental $0-60 \mathrm{~min}$ insulin to glucose area ratios produced a similar age-related pattern indicating that changes in insulin levels were independent of glucose concentrations. Gender did not affect these changes and multiple regression analysis showed that HLA haplotype sharing did not influence insulin responses in siblings of diabetic patients. Age and pubertal status must be carefully considered when interpreting intravenous glucose tolerance tests from patients suspected of having early abnormalities of carbohydrate metabolism.

Key words: Insulin, glucose, age, children, puberty.
The intravenous glucose tolerance test (IVGTT) has been used to identify individuals with early abnormalities of B-cell function. Loss of the first phase insulin response to intravenous glucose may precede oral glucose intolerance or overt diabetes [1].

In a preliminary report we showed that pubertal development is associated with an increase of basal and stimulated insulin responses in childhood siblings of diabetic patients [2]. We have now extended our study to determine the pattern of insulin responses following puberty. The combined analysis has allowed us to establish normal insulin responses to intravenous glucose during childhood, throughout puberty and into adult life.

\section{Subjects and methods}

One hundred seven islet cell antibody (ICA) negative subjects aged 5 to 50 years were studied. All were weighed and height measured and children up to 17 years were examined to assess the stage of pubertal devclopment using the criteria of Tanner for pubic hair and breast/ genitalia. All prepubertal (stage 1) boys had testes of less than $4 \mathrm{mls}$ volume [3]. Subjects were divided into 4 groups; Group I - stage 1 $(n=22)$, Group II $\cdots$ stages 2 and $3(n=18)$, Group III - stages 4 and
$5,<17$ years $(n=20)$, Group IV - adults, $>17$ years $(n=47)$. Four subjects were non-Caucasian, three in Group 11 ( 2 Asian, 1 West Indian) and one in Group III (West Indian). Groups I to III and four subjects from Group IV, i.e. a total of 64 subjects, were siblings of diabetic patients attending the Queen Elizabeth Hospital for Children, London and the Royal Berkshire Hospital, Reading, U.K. The remaining subjects were healthy adult volunteers with no family history of diabetes. Clinical details are shown in Table 1.

Siblings of diabetic patients were visited at home prior to the study and their families were HLA typed to determine whether the siblings were HLA-identical, haplo-identical or non-identical with the diabetic proband [4].

The weight-for-length index (WLI) was used as a measure of the relative body weight of subjects $[5,6]$. This index was chosen because, unlike other indices such as the body mass index, it does not correlate with height or age [6]. It was derived from the following formula:

$\mathrm{WLI}=\mathbf{A} \mathrm{B} \times 100 \%$

where $\mathrm{A}=\frac{\text { actual weight }(\mathrm{kg})}{\text { actual height }(\mathrm{cm})}$

and $B=\frac{50 \text { th percentile expected weight }(\mathrm{kg}) \text { for age }}{50 \text { th percentile expected height }(\mathrm{cm}) \text { for age }}$

The 50th percentile standards were taken from growth charts prepared by J.M. Tanner and R. H. Whitehouse [7].

All subjects were healthy, on a normal diet and on no medication. Subjects and/or their parents gave written informed consent, and the study was approved by the local Ethical Committees. 


\section{Protocol for the IVGTT}

Following an overnight fast (at least $10 \mathrm{~h}$ ), $0.5 \mathrm{~g} / \mathrm{kg}$ body weight (maximum $25 \mathrm{~g}$ ) $50 \%$ dextrose was infused at $20 \mathrm{~g} / \mathrm{min}$ via a Sage syringe pump (model 351, Arnold R. Horwell Ltd., London, UK). Zero time was taken as the point midway through the infusion. Blood was taken for glucose and insulin estimation at $-15,-5,1,3$, $5,7,10,15,20,30,45$ and $60 \mathrm{~min}$. Baseline blood samples were also taken for ICA measurements.

\section{Laboratory measurements}

Whole blood glucose was determined by a glucose oxidase method (YSI model 23AM glucose analyser, Yellow Springs Instrument Co., Yellow Springs, Ohio, USA) on the same day as the test. Heparinised blood was spun immediately at $4^{\circ} \mathrm{C}$ and stored at $-20^{\circ} \mathrm{C}$ until analysis for insulin was performed. Serum immunoreactive insulin was determined by a double antibody technique. The interassay coefficient of variation at $41 \mathrm{mU} / 1$ was $8.2 \%$ and the intra-assay variation at $38 \mathrm{mU} / 1$ was $3.9 \%$.

ICA were measured by the method distributed at the First International Workshop of standardisation of ICA [8]. Using the same pancreas, reagents and incubation conditions, the putative ICA standards currently being assessed by the Immunology and Diabetes Workshops gave end-point titres of 32 when tested 'blind' on two occasions [9]. Samples were read by 2 independent observers and the inter-assay reproducibility was \pm one doubling dilution.

\section{Statistical analysis}

First and second phase insulin responses to glucose were calculated as the incremental $0-10$ and $10-60 \mathrm{~min}$ areas above fasting concentrations. Glucose areas were calculated similarly. The glucose disposal ratc ( $\mathrm{k}$ value) was expressed as the slope of the semi-logarithmic decline of blood glucose over the $10-30 \mathrm{~min}$ period following administration of intravenous glucose. Ratios of the fasting insulin/ glucose $(\mathrm{I} / \mathrm{G})$ concentrations and of the incremental $0-60 \mathrm{~min} \mathrm{I} / \mathrm{G}$ areas were calculated.

Multiple regression analysis was used to determine the effects of pubertal group (I to III), age (years), sex, WLI and HLA status (i.e. HLA identity, haplo-identity or non-identity with the diabetic proband) on natural logged insulin concentrations. After dividing age into groups as shown in Figures 1 to 5, one-way analysis of variance was performed to determine if the mean insulin responses or ratios of insulin to glucose responses differed between the age groups. $95 \%$ confidence intervals for the difference between any 2 means were calculated to identify where the differences lay.

\section{Results}

The weight-for-length index did not differ significantly between the groups (Table 1).

\section{Data from the siblings of diabetic patients}

The following results were derived from a larger group of siblings than previously reported [2]. Increased numbers allowed us to examine whether HLA haplotype sharing with the diabetic proband influenced insulin responses to intravenous glucose, since this might bias any comparison between siblings and subjects with no family history of diabetes.

Siblings had median fasting blood glucose concentrations of $4 \mathrm{mmol} / \mathrm{l}$ (range 3.2-5.2) and $\mathrm{k}$ values of $2.4 \% / \mathrm{min}$ (range $1.3-5.5$ ). Table 2 shows the fasting in-
Table 1. Clinical details

\begin{tabular}{lllll}
\hline & $\begin{array}{l}\text { Group I } \\
\text { stage 1 }\end{array}$ & $\begin{array}{l}\text { Group II } \\
2 \text { and 3 }\end{array}$ & $\begin{array}{l}\text { Group III } \\
4 \text { and 5 }\end{array}$ & $\begin{array}{l}\text { Group IV } \\
\text { adult }\end{array}$ \\
\hline Sex (M/F) & $16 / 6$ & $9 / 9$ & $8 / 12$ & $28 / 19$ \\
Age \pm SD (ycars) & $8.9 \pm 2$ & $12.7 \pm 2.2$ & $15.2 \pm 1.3$ & $29.7 \pm 8.1$ \\
WLI \pm SD (\%) & $105 \pm 12$ & $100 \pm 13$ & $107 \pm 15$ & $107 \pm 12$ \\
HLA 1/haplo-I/NI & $4 / 12 / 6$ & $4 / 9 / 5$ & $6 / 9 / 5$ & a \\
\hline
\end{tabular}

WLI: weight-for-length index; HLA I/haplo-l/NI: HLA identical/ haplo-identical/non-identical with diabetic proband. "1 HLA I, 3 NI, 43 unrelated

Table 2. Fasting insulin concentrations and insulin responses to intravenous glucose: median values and ranges

\begin{tabular}{|c|c|c|c|c|}
\hline & Group I & Group II & Group III & Group IV \\
\hline $\begin{array}{l}\text { Fasting } \\
\text { insulin } \\
(\mathrm{mU} / \mathrm{l})\end{array}$ & $\begin{array}{l}7.2 \\
(2.6-15.5)\end{array}$ & $\begin{array}{l}11.9 \\
(8.2-22)\end{array}$ & $\begin{array}{l}13.3 \\
(8.5-23)\end{array}$ & $\begin{array}{l}6.9 \\
(2.2-16)\end{array}$ \\
\hline $\begin{array}{l}\Delta(0-10 \mathrm{~min} \\
\text { area } \\
(\mathrm{mU} / 1 / \mathrm{min})\end{array}$ & $\begin{array}{l}423 \\
(203-737)\end{array}$ & $\begin{array}{l}564 \\
(385-1454)\end{array}$ & $\begin{array}{l}728 \\
(258-1869)\end{array}$ & $\begin{array}{l}331 \\
(84-1047)\end{array}$ \\
\hline $\begin{array}{l}\Delta 10-60 \mathrm{~min} \\
\quad \text { area } \\
(\mathrm{mU} / 1 / \mathrm{min})\end{array}$ & $\begin{array}{l}610 \\
(341-1575)\end{array}$ & $\begin{array}{l}1239 \\
(563-2285)\end{array}$ & $\begin{array}{l}1754 \\
(398-2520)\end{array}$ & $\begin{array}{l}745 \\
(129-1553)\end{array}$ \\
\hline
\end{tabular}

sulin concentrations and first and second phase insulin responses in the four groups. Our previous finding of a significant rise in basal and stimulated insulin responses throughout puberty [2] was confirmed in this enlarged group.

\section{Influence of HLA haplotype sharing with the diabetic proband}

The number of siblings who were HLA identical, haplo-identical and non-identical with the diabetic proband in Groups I to III are shown in Table 1. Four subjects from Group IV were also siblings of diabetic patients; one was HLA identical, three were non-identical.

Multiple regression analysis examined the relationship between insulin response (basal and stimulated) and the variables pubertal group (I-III) and HLA status, i.e. HLA identity, haplo-identity or non-identity with the diabetic proband. F-values for HLA status were $0.37,2.16$ and 1.7 for fasting insulin, $\Delta 0-10$ and $\Delta 10-60 \mathrm{~min}$ areas respectively, all on 2.55 degrees of freedom (5\% critical value 3.17 ). None of these values are significant, indicating no demonstrable effect of HLA haplotype sharing on insulin levels in siblings of diabetic patients.

Insulin responses in mature pubertal subjects (Group III) and adults (Group IV)

The relationship between fasting insulin concentrations, first and second phase insulin responses and age in Group III and Group IV subjects is shown in Fig- 


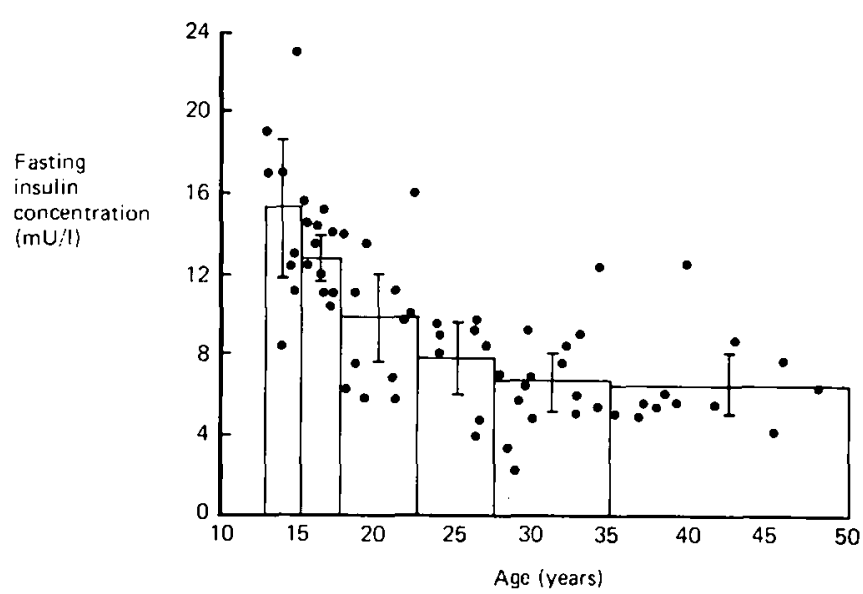

Fig.1. Fasting insulin concentrations in mature pubertal subjects (Group III) and adults (Group IV) in relation to age. Mean values with $95 \%$ confidence intervals are shown for different age groups

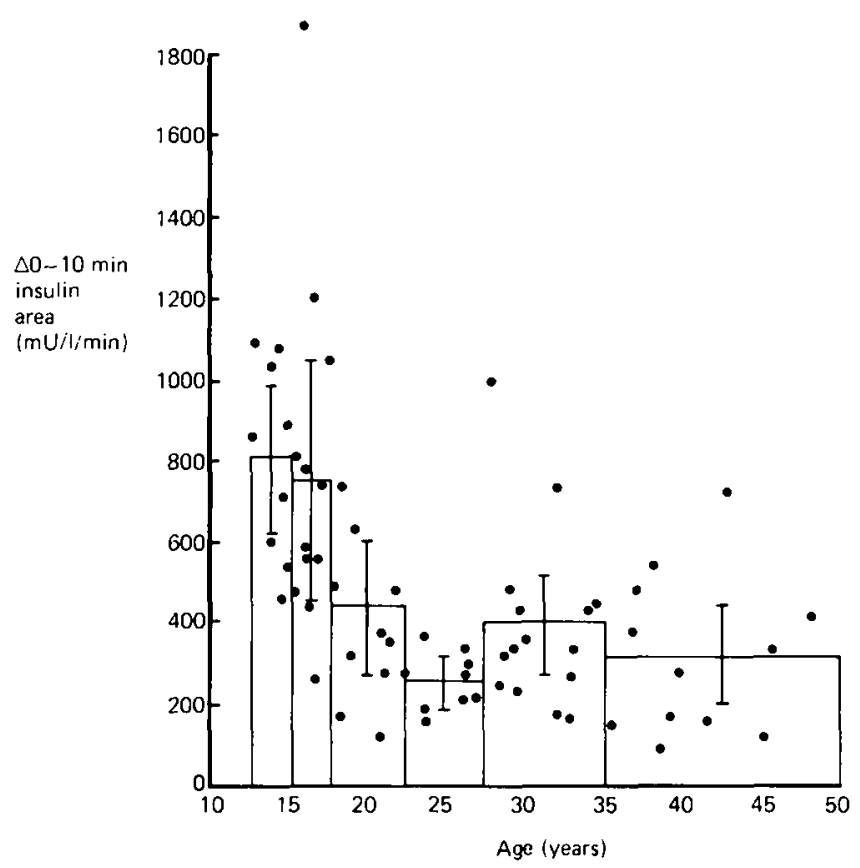

Fig.2. First phase insulin responses in mature pubertal subjects (Group III) and adults (Group IV) in relation to age. Mean values with $95 \%$ confidence intervals are shown for different age groups ures 1 to 3 . For analysis of data age was divided into the following 6 groups: $12.6-15,15.1-17.5,17.6-22.5$, 22.6-27.5, 27.6-35 and 35.1-50 years. Basal and stimulated insulin levels declined following puberty, the sharpest fall occurring between the 12.6-15 and 17.6-22.5 year groups. Mean concentrations for these two groups differed significantly; for fasting insulin concentrations, $p<0.001$, for $\Delta 0-10 \mathrm{~min}$ insulin areas, $p<0.01$ and for $\Delta 10-60 \mathrm{~min}$ insulin areas, $p<0.001$. A more gradual decline continued with increasing age but there was a significant difference between subsequent groups for fasting insulin concentrations only; between 17.6-22.5 and 27.6-35 year groups, $p<0.01$. There was no difference in basal or stimulated insulin levels between the 27.6-35 and 35.1-50 year groups $(p>0.4)$.

\section{Relationship between glucose and insulin responses from 5 to 50 years}

In contrast to insulin, there was no relationship between glucose (fasting, $\Delta 0-10$ and $\Delta 10-60 \mathrm{~min}$ areas)

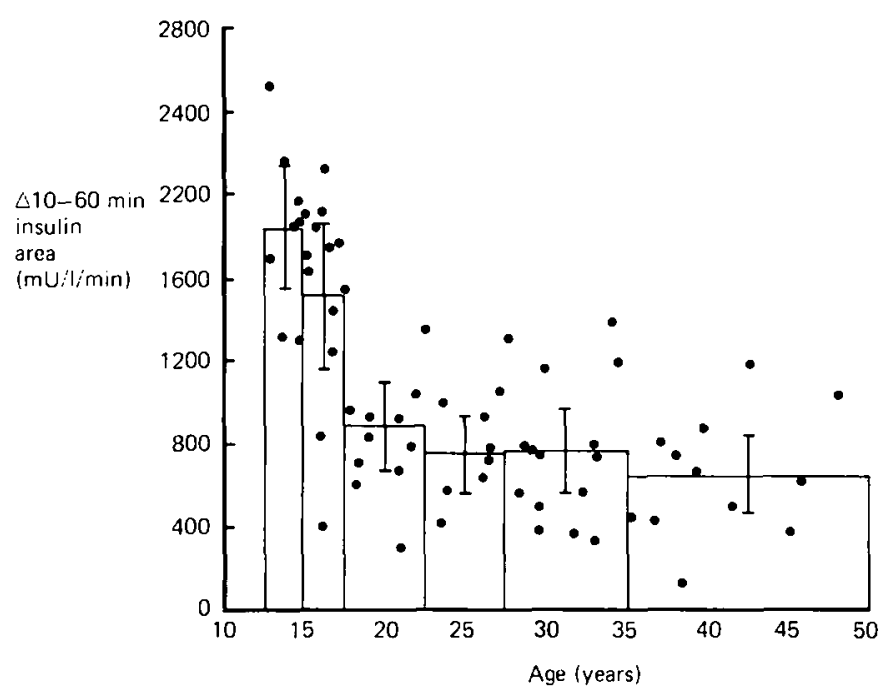

Fig.3. Second phase insulin responses in mature pubertal subjects (Group III) and adults (Group IV) in relation to age. Mean values with $95 \%$ confidence intervals are shown for different age groups

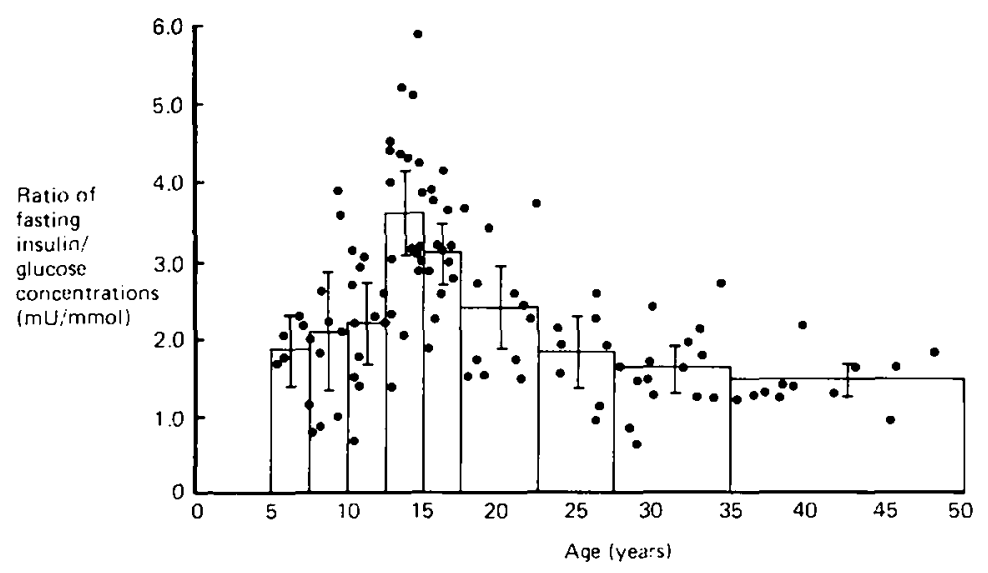

Fig.4. Fasting insulin to glucose ratios in relation to age. Mean values with $95 \%$ confidence intervals are shown for different age groups 


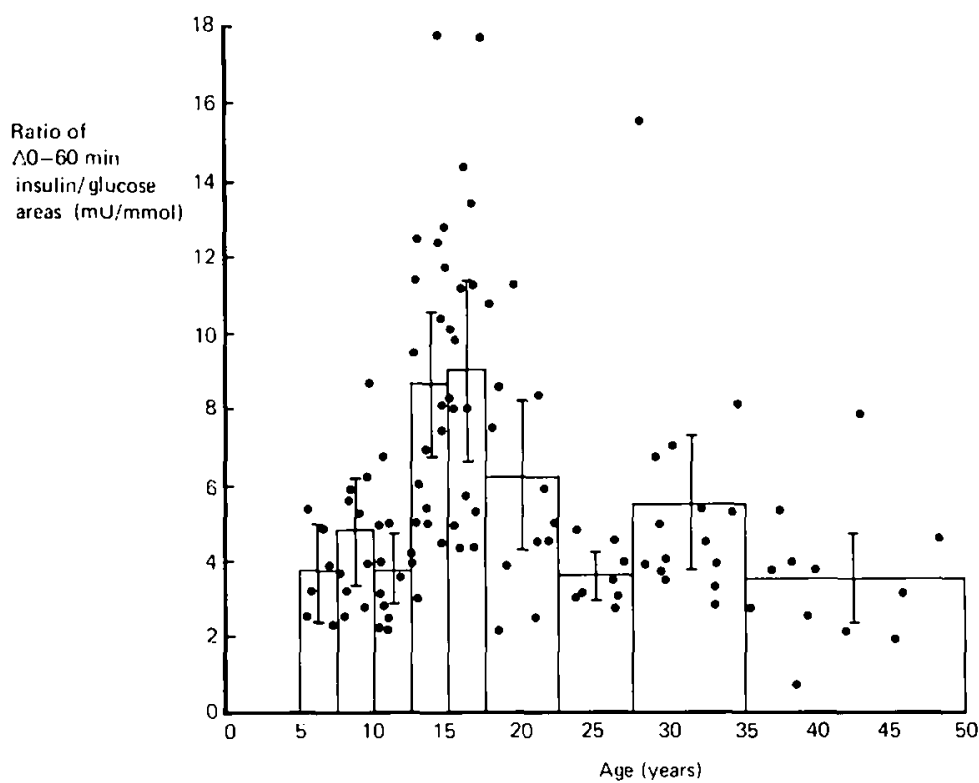

Fig.5. $\Delta 0-60 \mathrm{~min}$ insulin to glucose area ratios in relation to age. Mean values with $95 \%$ confidence intervals are shown for different age groups or glucose disposal rates and age or pubertal group. Figures 4 and 5 show the fasting $I / G$ ratios and the $\Delta 0-60 \mathrm{~min} \mathrm{I} / \mathrm{G}$ area ratios plotted against age. For purposes of analysis age was divided into the following groupings: 5-7.5, 7.6-10, 10.1-12.5 years, subsequent groups as described previously. The pattern of change closely resembles the changes in basal and stimulated insulin levels with age (not shown). Fasting $\mathrm{I} / \mathrm{G}$ ratios and $\Delta 0-60 \mathrm{~min} \mathrm{I} / \mathrm{G}$ area ratios were higher in the two groups between 12.6 and 17.5 years than in the three groups between 5 and 12.5 years $(p<0.01)$ (Figs. 4 and 5 ). From 17.5 years onwards the decline in basal and stimulated insulin to glucose ratios (Figs. 4 and 5) was similar to the fall in insulin levels alone (Figs. 1 to 3 ).

\section{Results from males and females}

Two multiple regression analyses were performed to examine (1) the rise in insulin levels during puberty (Groups I-III) and (2) the age-related decline in insulin levels following puberty (Groups III and IV). After adjustment for pubertal group (I-III) and age (Group III and IV), sex did not influence basal and stimulated insulin levels $(p>0.05$ for fasting insulin concentrations, $\Delta 0-10$ and $\Delta 10-60 \mathrm{~min}$ areas).

\section{Discussion}

The insulin responses to intravenous glucose differ significantly between children at different stages of pubertal development [2]. Insulin levels were much higher in children in late puberty than in adults, whose responses were similar to those of prepubertal children. We have now extended our previous study to show the pattern of insulin responses following puberty.

Our study population unavoidably comprised two distinct groups of subjects, since ethical permission to study 'normal' children in this way would not be forthcoming. The children were all siblings of Type 1 (insulin-dependent) diabetic patients, whereas the majority of adults had no family history of diabetes. In an attempt to ensure that none of the siblings had early Bcell damage, we checked that they were ICA negative and thus at low risk of developing diabetes [4, 10]. There was no evidence of abnormal carbohydrate metabolism in that they had normal fasting glucose concentrations [11] and glucose disposal rates [12]. With regard to the HLA status of the childhood siblings, Hollander et al. [13] found that nine HLA-identical siblings had higher first phase insulin responses that non-diabetic matched control subjects, but the same group now question their original findings in a more recent report [14]. Lindgren et al. [15] also found no differences in insulin response between HLA identical, haplo-identical and non-identical siblings. We found that in our group of 60 children haplotype sharing did not influence the basal and stimulated insulin responses of siblings.

Fasting insulin and first and second phase insulin responses to intravenous glucose fall after puberty until the third decade after which levels appear constant throughout the fourth decade. Decreasing insulin responses following puberty were suggested by Lindgren et al. [15] but staging of pubertal development was not performed in their subjects. This fall following puberty is an important new observation because it could be mistaken in an individual for early B-cell failure [1]. Furthermore, it may help to explain some of the conflicting results which have arisen from studies confined to adult subjects using the IVGTT. These studies have been reviewed thoroughly by Davidson [16] and variously report increased, decreased and similar insulin responses in old versus young subjects. This variation may be explained in part by the different ages of the young subjects who were studied. 
We used insulinogenic indices (fasting $\mathrm{I} / \mathrm{G}$ ratios and $\Delta 0-60 \mathrm{~min} \mathrm{I} / \mathrm{G}$ area ratios) to demonstrate that the pattern of basal and stimulated insulin responses in relation to age is independent of glucose levels. The inference is that these changes are associated with changes in insulin resistance. Increasing insulin resistance with advancing puberty has been reported in studies using the euglycaemic insulin clamp in children $[17,18]$. Our data suggest that insulin resistance falls following puberty until the third decade with no further change in the fourth decade.

In conclusion, this study emphasises the need for a very large pool of data from normal individuals to allow accurate interpretation of the IVGTT. The precision of the IVGTT is limited by the wide variability of insulin responses in normal individuals $[19,20]$. Some of this variability may be explained by the large differences we have found in the insulin responses of children and adults of different ages and stages of development. Analysis of insulin to glucose ratios suggests that these changes reflect an increase of insulin resistance from childhood until late puberty, followed by a decline during early adult life.

Acknowledgements. We thank Dr J.B.Burke and Dr N.P.Mann, Consultant Paediatricians at The Royal Berkshire Hospital, Reading for permission to study patients under their care. This project was supported by grants from The Joint Research Board of St Bartholomew's Hospital, Nordisk-UK, Eli Lilly \& Co. Ltd and the Leverhulme Trust.

\section{References}

1. Srikanta S, Ganda OP, Gleason RE, Jackson RA, Soeldner JS, Eisenbarth GS (1984) Pre-Type 1 diabetes. Linear loss of beta cell response to intravenous glucose. Diabetes 33: 717-720

2. Smith CP, Archibald HR, Thomas JM, Tarn AC, Williams AJK, Gale EAM, Savage MO (1988) Basal and stimulated insulin levels rise with advancing puberty. Clin Endocrinol 28: 7-14

3. Zachmann M, Prader A, Kind HP, Hafliger H, Budliger H (1974) Testicular volume during adolescence. Cross-sectional and longitudinal studies. Helv Paediatr Acta 29: 61-72

4. Gorsuch AN, Spencer KM, Lister J, Wolf E, Bottazzo GF, Cudworth AG (1982) Can future Type 1 diabetes be predicted? A study in families of affected children. Diabetes 31: 862-866

5. McLaren DS, Read WWC (1975) Weight/length classification of nutritional status. Lancet II: 219-221

6. DuRant RH, Linder CW (1981) An evaluation of five indexes of relative body weight for use with children. J Am Diet Assoc 78: $35-41$
7. Castlemead Publications, Publishing Division of Creaseys of Hertford Ltd, Castleford, Hertford SG14 11h. Boys Ref. GDB 11A, Girls Ref. GDG 12A

8. Gleichmann H, Bottazzo GF (1987) Progress towards standardization of cytoplasmic islet-cell antibody assay. Diabetes 37: $578-584$

9. Bonifacio R, Dawkins RL, Lernmark A (1987) Report of the Second International Workshop on the standardization of cytoplasmic islet-cell antibodies. Diabetologia 30:273

10. Tarn AC, Thomas JM, Dean BM, Ingram D, Schwarz G, Bottazzo GF, Gale EAM (1988) Predicting insulin-dependent diabetes. Lancet I: $845-850$

11. World Health Organization Expert Committee on Diabetes Mellitus. Report (1985) World Health Organization Technical Report Series No.727, Geneva

12. Lundbaek K (1962) Intravenous glucose tolerance as a tool in definition and diagnosis of diabetes mellitus. $\mathrm{Br}$ Med $\mathrm{J} \mathrm{I}$ : 1507-1513

13. Hollander PH, Asplin CM, Kniaz D, Hansen JA, Palmer JP (1982) Beta-cell dysfunction in nondiabetic HLA identical siblings of insulin-dependent diabetics. Diabetes 31: 149-153

14. Johnston C, Raghu P, McCulloch DK, Beard JC, Ward WK, Klaff LJ, McKnight B, Bergman RN, Palmer JP (1987) Beta-cell function and insulin sensitivity in nondiabetic HLA-identical siblings of insulin-dependent diabetes. Diabetes 36: 829-837

15. Lindgren F, Dahlquist G, Efendic S, Moller E, Persson B, Thalme B, Landin Olsson M (1987) Glucose-induced insulin response and insulin sensitivity is not related to HLA-type but to age in young siblings of Type 1 (insulin-dependent) diabetic patients. Diabetologia 30: 727-732

16. Davidson MB (1980) The effect of aging on carbohydrate metabolism: a review of the English literature and a practical approach to the diagnosis of diabetes mellitus in the elderly. Metabolism 28: $688-705$

17. Amiel SA, Sherwin RS, Simonson DC, Lauritano AA, Tamborlane WV (1986) Impaired insulin action in puberty. A contributing factor to poor glycemic control in adolescents with diabetes. N Engl J Med 315: 215-219

18. Bloch CA, Clemons P, Sperling MA (1987) Puberty decreases insulin sensitivity. J Pediatr 110: 481-487

19. Ganda OP, Day JL, Soeldner JS, Connon JJ, Gleason RE (1978) Reproducibility and comparative analysis of repeated intravenous and oral glucose tolerance tests. Diabetes 27: 715-725

20. Smith CP, Tarn AC, Thomas JM, Overkamp D, Corakci A, Savage MO, Gale EAM (1988) Between and within subject variation of the first phase insulin response to intravenous glucose. Diabetologia 31: 123-125

Received: 25 January 1988

and in revised form: 29 April 1988

Dr. C.P.Smith

Department of Diabetes and Immunogenetics

St. Bartholomew's Hospital

London EC1A 7BE

UK 